\title{
NOS FIOS DA MEMÓRIA, A EUROPA SONHADA POR UM HUMANISTA
}

\author{
Claudia Maria Pereira de Almeida*
}

Resumo: Em Éducation européenne ${ }^{1}$ e As pipas, respectivamente o primeiro e o último romances de Romain Gary, a resistência durante a Segunda Guerra Mundial é contada a partir das impressões de dois adolescentes. Entretanto, esses textos não se resumem a narrativas de guerra. Trata-se, na verdade, de reflexões sobre a enorme dificuldade experimentada pelos homens para suportar a estrangeiridade, a diferença e a alteridade. A retomada do tema e dos cenários fecha um círculo na obra de Romain Gary. Os dois livros estão separados por um intervalo de trinta e cinco anos e unidos por inquietações semelhantes. A memória desempenha um papel fundamental: Romain Gary insistia em lembrar as desventuras do homem, talvez com o objetivo de estabelecer um novo conceito de humanidade.

Palavras-chave: Romain Gary; memória; guerra; alteridade.

Abstract: In Éducation européenne and Les cerfs-volants, the first and the last of Romain Gary's novels respectively, the Resistance during World War II is told by two teenagers according to their own impressions. Nevertheless, these texts are not just war narratives; they are rather reflections about the enormous

* Universidade do Estado do Rio de Janeiro e Colégio Pedro II.

${ }^{1}$ Existe uma tradução em português de European education, a versão definitiva em inglês de Éducation européenne, que recebeu o título de Orouxinol sempre retorna. A referência consta na bibliografia por entendermos que é pertinente para o leitor brasileiro. Entretanto, em nosso texto, fazemos sempre a tradução da versão definitiva em francês. 
difficulty mankind has to bear the strangeness, the difference and the otherness. The resumption of both theme and scenery closes a circle in Romain Gary's literary work. The two books are separated by thirty-five years and linked by similar worries. Memory plays an important role in these aspects of the Resistance: Romain Gary insists in recalling the misfortunes of man with the possible objective of establishing a new concept of humankind.

Keywords: Romain Gary; memory; war; otherness.

A verdade é que há momentos na história, momentos como este que vivemos, em que tudo o que impede o homem de se desesperar, tudo que permite que ele creia e continue a viver, tudo precisa de um esconderijo, um refúgio. As vezes, esse refúgio não passa de uma canção, um poema, uma música, um livro. Gostaria que meu livro fosse um desses refúgios, que ao abri-lo, depois da guerra, quando tudo estiver terminado, os homens encontrem seu bem intacto, que eles saibam que alguns nos forçaram a viver como animais, mas que não puderam nos forçar a nos desesperarmos. Não há arte desesperada - o desespero é apenas uma falta de talento. ${ }^{2}$ (GARY, 1956, p. 77-76) ${ }^{3}$

As guerras, em geral, marcam profundamente a literatura. No século XX, as duas guerras mundiais, que se desenrolaram

\footnotetext{
${ }^{2}$ Salvo indicação nas referências bibliográficas, as traduções são feitas por mim. Nesses casos, indico o texto original nestas notas. Quando usar uma tradução publicada, não indicarei o texto original.

${ }^{3}$ No original "La vérité, c'est qu'il y a des moments dans l'histoire, des moments comme celui que nous vivons, où tout ce qui empêche l'homme de désespérer, tout ce qui lui permet de croire et de continuer à vivre, a besoin d'une cachette, d'un refuge. Ce refuge, parfois, c'est seulement une chanson, un poème, une musique, un livre. Je voudrais que mon livre soit un de ces refuges, qu'en l'ouvrant, après la guerre, quand tout sera fini, les hommes retrouvent leur bien intact, qu'ils sachent qu'on a pu nous forcer à vivre comme des bêtes, mais qu'on n'a pas pu nous forcer à désespérer. Il n'y a pas d'art désespéré - le désespoir, c'est seulement un manque de talent.".
} 
na Europa e implicaram vários países desse continente (além de outros), deixaram rastros persistentes na literatura produzida, principalmente, por europeus. Os quatro anos e meio de Ocupação alemã na França (maio de 1940 a dezembro de 1944), o movimento de Resistência, a Shoá, o pós-guerra deixaram marcas importantes em escritores de língua francesa que viveram esse período ou que herdaram as lembranças de parentes e amigos.

Romain Gary é um desses escritores. A Segunda Guerra Mundial perpassa sua obra literária como tema principal ou como alusão insistente. Combatente que atende o apelo de 18 de junho de 1940 feito pelo General de Gaulle, ele retorna da guerra com medalhas, cicatrizes e um manuscrito. Começava a carreira de um escritor que defenderá ardorosamente um humanismo total, sem limites e, talvez por isso mesmo, utópico.

\section{Batatas e pipas: pistas para uma educação europeia}

Romain Gary não é francês de nascimento. Filho de mãe russo-judia e de pai russo (pelo menos na certidão), chega ao mundo em 1914, em Vilnius (Lituânia, na época parte do Império russo). Aos 14 anos, parte para a França. A partir desse momento, esse será seu país e o francês sua língua. Convocado na Segunda Guerra, em pouco tempo, se juntou ao general de Gaulle no combate pela libertação da França. Em 1944, ao retornar da guerra, traz o manuscrito de seu primeiro livro e ingressa na carreira diplomática.

Esse texto foi publicado, primeiro, na tradução inglesa The forest of anger -, ainda em 1944. No ano seguinte, Éducation européenne, o original em francês, obteve um grande sucesso e ganhou o Prix des critiques. Certamente, trata-se de um dos primeiros textos-depoimento sobre a Segunda Guerra. A trama se passa na floresta polonesa e a maioria dos personagens é formada por membros da Resistência (maquisards), movimento que nesse texto, está em primeiro plano. 
Entretanto, não se pode restringir o alcance do romance somente à narrativa do quotidiano dos resistentes. Apesar de um grande espaço ser dedicado às práticas de guerra e à descrição das dificuldades enfrentadas pelos combatentes, Romain Gary se afasta do caminho fácil da simples e inquestionável acusação das atrocidades cometidas pelo exército alemão. Em Éducation européenne, a condenação de um país e de seu povo é substituída por uma análise aguda da desumanização do homem quando se vê diante da alteridade.

Nesse livro, Janek, um adolescente de cerca de 13 anos, se esconde em um buraco de três metros de altura por quatro de largura, construído por seu pai. Esse, além do esconderijo, também providencia dez sacos com cinquenta quilos de batatas cada um e uma pistola automática com cinquenta cartuchos de munição. Tudo isso com um único objetivo: preservar a vida do terceiro e único filho vivo. Entretanto, forçado pelas circunstâncias, Janek vai se juntar à Resistência e seguirá um percurso de aprendizagem nesse ambiente.

Entre os resistentes, um vai se aproximar particularmente de Janek: Dobranski, que escreve um livro sobre o que vê e vive. Para Dobranski, a escrita é um meio eficaz de conservar o bem do homem, de impedir que a barbárie destrua todos os traços de humanidade que lhe são característicos. Dando provas de rara clarividência entre os que atravessaram o período da guerra, Dobranski estabelece uma diferença entre patriotismo e nacionalismo e propõe bases para o respeito da alteridade: "O patriotismo é o amor pelos seus. O nacionalismo é o ódio dos outros. Russos, americanos, todos... Há uma grande fraternidade que se prepara no mundo, os alemães terão valido pelo menos para isso..." 4 (GARY, 1956, p. 246). Desde o seu primeiro livro, Romain Gary apresenta uma visão do homem intrinsecamente otimista.

\footnotetext{
${ }^{4}$ No original: "Le patriotisme, c'est l'amour des siens. Le nationalisme, c'est la haine des autres. Les Russes, les Américains, tout ça... Il y a une grande fraternité qui se prépare dans le monde, les Allemands nous auront valu au moins ça...".
} 
Esse romance de estreia garante a conservação de uma memória de guerra sem, no entanto, cultuá-la. Romain Gary não a usará como base de sua obra literária, mas o tema será recorrente em seus textos. Em seu último romance, As pipas, a memória de guerra e a de uma certa França retornam com força.

Esse volume tem como origem a renúncia a um projeto. Em 1976 ou 1977, Romain Gary foi convidado a escrever um livro sobre os Compagnons de la Libération. Criada em 1940, pelo general de Gaulle, a Ordem da Liberação tinha o objetivo de "recompensar de uma maneira inteiramente original a dedicação de alguns dos que - tão pouco numerosos no início (pouco mais de $2.500 \mathrm{em} 14$ de julho de 1940) - aceitaram arriscar tudo para participar de uma aventura cujo desfecho era ignorado em 1940." Romain Gary, ele mesmo Compagnon de la Libération, aceita o convite e começa o trabalho elaborando um questionário que é enviado aos outros Compagnons e fazendo várias entrevistas. Todavia, ao fim de um ano, o escritor desiste do projeto. De acordo com Tzvetan Todorov,

A razão dessa recusa de retratar os heróis não se restringe à relutância de Gary em fazer literatura com o sofrimento e a morte de seus próximos ("eles não morreram por grandes tiragens"). Mais profundamente, ele constata que o herói é uma encarnação dos valores que identifica como "masculinos": força, coragem, abnegação, capacidade de sacrifício (trata-se de Jean Moulin e Pierrre Brossolette, ídolos do narrador de Gros-Câlin). Gary está pronto para admirar os heróis, mas não para esquecer o outro lado da medalha: esses mesmos valores nutrem o machismo, responsável pelos maiores males. ${ }^{6}$ (TODOROV, 2002, p.100-101)

\footnotetext{
${ }^{5}$ No original: "récompenser d'une manière tout à fait originale le dévouement de certains de ceux qui - si peu nombreux au départ (ils ne sont guère plus de 2.500 le 14 juillet 1940) - ont accepté de tout risquer pour participer à une aventure dont on ignorait en 1940 quel serait son aboutissement". Disponível em: http://www.odredelaliberation.fr/fr_doc/1_1_2_creation.html. Acesso em 08/10/2009.

${ }^{6}$ No original: "La raison de ce refus de peindre les héros n'est pas seulement
} 
Ao invés da heroicização dos Compagnons de la Libération, Romain Gary vai escrever uma homenagem aos que tinham lutado para libertar a França do invasor. Ele retoma a temática da Resistência, tendo como cenário, desta vez, a própria França.

Ludo, o jovem narrador, é sobrinho de Ambroise Fleury, um carteiro rural que fabrica pipas - o carteiro biruta, de acordo com os moradores de Cléry. A memória prodigiosa de Ludo é conhecida no vilarejo e será posta a serviço dos resistentes durante a Segunda Guerra. Da mesma forma, as pipas de seu tio transmitirão mensagens em código ou farão subir ao céu figuras emblemáticas da História da França, à guisa de protesto ou de encorajamento à resistência.

$\mathrm{Na}$ verdade, as pipas abrem um leque simbólico bastante vasto. De acordo com Ralph Schoolcraft,

Gary quer celebrar uma certa altivez de atitude, uma "altitude", digamos assim, sempre nos lembrando que esses ideais são frágeis e devem ser manipulados com cuidado e arte. Não se deve esquecer, no entanto, que as pipas são objetos que voam e, em sua vulnerabilidade, lembram o extremo perigo que viveram em seu quotidiano todos os pilotos da esquadrilha Lorraine, de que fazia parte Gary. ${ }^{7}$ (SCHOOLCRAFT, 2007, p.151)

que Gary répugne à faire de la littérature avec la souffrance et la mort de ses proches ("ils ne sont pas tombés pour des gros tirages"). Plus profondément, il constate que le héros est une incarnation des valeurs qu'il identifie comme "masculines": force, courage, abnégation, capacité de sacrifice (c'est Jean Moulin et Pierre Brossolette, idoles du narrateur de Gros-Câlin). Gary est prêt à admirer les héros, mais non à oublier l'envers de la médaille: ces mêmes valeurs nourrissent le machisme, responsable, lui, des plus grands maux.".

${ }^{7}$ No original: "Gary veut célébrer une certaine hauteur d'attitude, une "altitude" pour ainsi dire, tout en nous rappelant que ces idéaux sont fragiles et doivent être maniés avec soin et art. Il ne faut pas oublier, pourtant, que les cerfs-volants sont des objets qui volent et, dans leur vulnérabilité, rappellent l'extrême danger qu'ont vécu au quotidien tous les pilotes de l'escadrille "Lorraine", dont faisait partie Gary.". 
As batatas de Janek e as pipas de Ambroise Fleury - alimento material e conforto moral, respectivamente tornaram-se fundamentais para a sobrevivência dos resistentes e da Resistência. São também decisivas para que Janek e Ludo percebam a construção de relações entre os mesmos e os outros. $\mathrm{O}$ percurso de aprendizagem dos dois adolescentes inclui o contato com estrangeiros que, a partir de um certo momento, são vistos simplesmente como europeus, ou seja, indivíduos que compartilham uma história e valores. Essa educação europeia leva ambos a narrar suas impressões e a assegurar que as lembranças não se esmaeçam. Na pena de Romain Gary, a memória da guerra ganha contornos filosóficos e essencialmente otimistas.

\section{Dedicatórias importantes e reveladoras}

A dedicatória não é uma prática de Romain Gary: poucos volumes são dedicados a amigos ou a personagens. Entretanto, os dois textos que estudamos aqui - primeiro e último da obra garyana - têm dedicatórias semelhantes. Éducation européenne lembra um colega falecido: "À memória de meu camarada, o francês livre Robert Colcanap". Esse, o caçula da esquadrilha Lorraine, fora vítima de um acidente aéreo, em 11 de novembro de 1943, dia em que se comemora o armistício da Primeira Guerra. A primeira dedicatória de Romain Gary se dirige, pois, a um desconbecido que, aos vinte e dois anos, morre sem ter tido tempo de se tornar um herói. Na ocasião do acidente, Colcanap era o navegador do segundo-tenente Yves Laurent. Durante um voo de treinamento, os dois motores do avião apresentaram pane e, para não aterrissar em um terreno onde militares se exercitavam, o segundo-tenente Laurent deixou o avião se espatifar contra blocos de concreto. Assim, é ele que é tratado como verdadeiro

\footnotetext{
${ }^{8}$ No original: "À la mémoire de mon camarade le Français libre Robert Colcanap".
} 
herói. A primeira dedicatória de Romain Gary inaugura, pois, um procedimento importante para o escritor: lembrar os ignorados pelos textos históricos, debruçar-se sobre o que é supostamente menos importante, valorizar o detalhe que pode conduzir à vida. Não se trata, pois, de uma condecoração póstuma, concedida aos que se sacrificaram, mas de uma lembrança dos que foram esquecidos.

A dedicatória anuncia o tipo de recordação que será feito no romance: os dramas individuais dos indivíduos desconhecidos da História são contados em toda sua dor. Alguns desses dramas são narrados de maneira pungente: as crises de loucura de Stanezyck, cujas filhas depois de terem sido violentadas por soldados alemães, tinham sido enviadas para um bordel; ou o sofrimento de pan Jozef, o colaboracionista, dono de cabaré, que joga dos dois lados e cuja esposa, diante de seus próprios olhos, também foi violentada por um policial da Kommandantur. Esses exemplos confirmam o tratamento particular dado a cada ser: o estupro, prática corrente nas guerras, não é mostrado por números, que, no entanto, impressionam, mas é exposto em suas consequências dolorosas, que atingem singularmente o indivíduo. A guerra transformada em texto por Romain Gary destaca o sofrimento pessoal do homem e não o de um povo.

Em seu último romance, As pipas, a dedicatória "À memória", indica um caminho diferente, que privilegia a generalização. No momento de fechar sua obra, Romain Gary despersonaliza a lembrança e a torna anônima e abrangente. Essa é a única dedicatória que não se dirige nem a uma pessoa nem a um personagem.

Desde a primeira página, fica claro que essa dedicatória é realmente um anúncio, quase um subtítulo do livro, talvez mesmo seu equivalente: "[...] vivemos uma época em que os franceses procuram muito mais esquecer do que lembrar." (GARY, 1981, p. 1). Efetivamente, esse texto também é uma ação no sentido de completar algumas lacunas, sobretudo para as novas gerações 
que não viveram a guerra. De acordo com Paul Ricoeur, "a busca da lembrança confirma de fato uma das principais finalidades do ato de memória, a saber, a de lutar contra o esquecimento, a de arrancar pedacinhos de lembrança da rapacidade do tempo (Agostinho dixit), ao sepultamento no esquecimento"(RICOEUR, 2000, p. 36).

Para Gary, talvez mais do que a rapacidade do tempo, o verdadeiro inimigo é uma certa memória oficial que a História estabelece e difunde. O que interessa a Romain Gary, no entanto, é o relato que ainda não foi feito ou que o foi rápido demais.

É justamente nesse sentido que se deve ler a última frase de As pipas, que poderia parecer um pouco deslocada: "Termino finalmente esta narrativa escrevendo uma vez mais os nomes do pastor André Trocmé e o de Le Chambon-sur-Lignon, pois nada melhor poderia ser dito" (GARY, 1981, p. 221).

Chambon-sur-Lignon é uma pequena cidade, na Auvérnia, onde viviam o pastor André Trocmé e sua esposa Magda. Durante a Segunda Guerra, eles conseguiram operacionalizar mecanismos que asseguraram alojamento e fuga a milhares de judeus. Encorajando a população a se engajar nessa obra, o casal pode salvar cerca de 5.000 judeus, em sua maioria crianças.

O memorial Yad Vashem outorgou-lhes a medalha dos Justos das Nações. Em 1988, os moradores de Chambon-surLignon e de distritos vizinhos receberam, coletivamente, a mesma honraria. Somente duas cidades tiveram essa distinção: Chambonsur-Lignon e Nieuwlande, um vilarejo holandês.

Romain Gary poderia ter situado seu livro em Chambonsur-Lignon e contado os esforços que fazia a população para salvar os perseguidos. Mas isso não lhe convinha, pois correria o risco de transformar a memória em culto. Ele prefere citar e insistir na citação, de modo que a recordação se conserve sem ofuscação ou deslumbramento. A memória que Romain Gary transforma em texto, tanto em Éducation européenne como em As pipas, abre um caminho entre os dois perigos da rememoração, indicados por Todorov: 
[...] nela mesma e sem nenhuma outra restrição, a "memória" não é nem boa nem ruim. Os benefícios que dela se espera tirar podem ser neutralizados e mesmo desviados. De que maneira? Primeiramente, pela própria forma que tomam nossas reminiscências, navegando constantemente entre dois recifes que se complementam: a sacralização, ou isolamento radical da lembrança, e a banalização, ou assimilação abusiva do presente ao passado. ${ }^{9}$ (TODOROV, 2000, p. 176)

Ainda que as atrocidades perpetradas na guerra sejam mostradas, nenhum dos dois textos insiste, por exemplo, na Shoá. Romain Gary, ele mesmo judeu, não identifica no massacre dos judeus um acontecimento que deva ser mais destacado do que outras barbaridades. Em Toda a vida pela frente, livro que publicou com o pseudônimo Émile Ajar, podemos ver explicitamente essa posição. O personagem Kadir Youssef, muçulmano, chega à casa de Madame Rosa - ex-prostituta judia que cuida dos filhos de prostitutas - para buscar seu filho, onze anos depois de tê-lo deixado. Em uma discussão com Madame Rosa, ele afirma: "Madame, sou perseguido sem ser judeu. Vocês não têm o monopólio. Acabou-se o monopólio judeu, Madame. Existem outras pessoas, além dos judeus, que também têm o direito de serem perseguidas" (GARY, 1986, p. 102). A fala do personagem reflete bem a postura do escritor: Romain Gary recusa a prevalência de uma catástrofe sobre outra, pois todas provém da desumanização e, por isso, são igualmente dolorosas. O reconhecimento de uma hierarquia nas perseguições sofridas por povos ou etnias conduziria à sacralização do acontecimento,

\footnotetext{
${ }^{9}$ No original: "en elle-même, et sans aucune autre restriction, la "mémoire" n'est ni bonne ni mauvaise. Les bénéfices que l'on espère en tirer peuvent être neutralisés, voire dévoyés. De quelle manière? Tout d'abord par la forme même que prennent nos réminiscences, naviguant constamment entre deux écueils complémentaires: la sacralisation, ou isolement radical du souvenir, et la banalisation, ou assimilation abusive du présent au passé.".
} 
o que promoveria o esquecimento - ou apagamento? - de outros morticínios. A defesa irônica do "direito à perseguição" expõe a existência de anônimos - esquecidos - que ocuparam espaços reduzidos no discurso histórico ou que receberam pouca atenção no âmbito midiático.

A banalização, outro extremo identificado por Todorov, assimila os acontecimentos presentes aos do passado, o que traz o risco de reduzir bastante o alcance de ambos. Quando essa assimilação tem êxito, identifica-se uma forte tendência a procurar soluções antigas para problemas novos. A cegueira e a alienação são os resultados mais comuns. Exemplificando seu ponto de vista, Todorov afirma: "Quando se usa o termo "nazista" como simples sinônimo de "patife", qualquer lição de Auschwitz fica perdida. O próprio personagem de Hitler, particularmente, é constantemente adaptado a todas as situações, usado para tudo - e, no entanto, o genocídio dos judeus é considerado único"10 (GARY, 2000, p. 179).

$\mathrm{Na}$ escrita garyana, a memória que focaliza o drama individual e a que resgata a abrangência do acontecimento escapam à facilidade da sacralização e da banalização. O escritor faz dessas memórias uma estratégia em prol de uma "justa causa" (TODOROV, 2000, p. 1988), a saber a garantia de que o passado será conhecido no presente e que poderá contribuir para a construção de um humanismo baseado no reconhecimento fraterno do outro.

Nos dois textos ficcionais, encontramos atividades rotineiras dos movimentos de resistência e momentos particularmente dolorosos dos indivíduos. Esses fragmentos de lembranças são, entretanto, eles também, fictícios. Romain Gary não viveu a Resistência, pois combatia no campo de batalha. Esse

\footnotetext{
${ }^{10}$ No original: "Quand on utilise le terme «nazi» comme simple synonyme de «salaud», toute leçon d'Auschwitz est perdue. Le personnage même de Hitler, en particulier, est régulièrement accomodé à toutes les sauces, on le trouve partout - alors même que le génocide des juifs est censé être unique.".
} 
"curto-circuito entre memória e imaginação"11 (RICOEUR, 2000, p. 5) garante que sejam lembrados os que o eram pouco ou nada e que sejam evocadas rememorações de pessoas anônimas que viveram dramas pessoais sem que estes pertençam à memória de guerra oficial. Essas ficções, que resgatam elementos não tão fictícios, ilustram as dificuldades que sente o homem para aceitar a alteridade em todos os seus aspectos.

\section{A busca de um humanismo absoluto}

A construção da Europa sempre esteve entre as reflexões de Romain Gary. Fabrice Larat, que defendeu uma tese de Doutorado a respeito dessa questão, opina:

De fato, seja através do problema de sua identidade nos assuntos abordados em sua obra, mas também em alguns combates e tomadas de posição públicas, encontra-se sempre o mesmo tema: a Europa, suas raízes, seus valores, sua existência presente e futura. Um outro Romain Gary aparece assim, o jovem diplomata visionário implicado na refundação da ordem europeia do pós-guerra. O intelectual humanista que defende uma concepção de engajamento na contramão da que prevalece na sociedade de sua época, o promotor de uma identidade europeia que não seria o produto de uma reflexão acadêmica, mas o resultado de uma experiência pessoal e transcendida pela escrita. ${ }^{12}$ (LARAT, 1999, p. 2-3)

${ }^{11}$ No original: "court-circuit entre mémoire et imagination".

${ }^{12}$ No original: "En fait que ce soit à travers le problème de son identité dans les sujets abordés dans son oeuvre, mais aussi dans certains de ses combats et prises de positions publiques, on retrouve toujours le même thème, celui de l'Europe, de ses racines, de ses valeurs et de son existence présente et future. Un autre Romain Gary apparaît ainsi, le jeune diplomate visionnaire impliqué dans la refonte de l'ordre européen d'après guerre. L'intellectuel humaniste défendant une conception de l'engagement qui va à contre-courant de celle qui prévaut dans la société de son époque, le promoteur d'une identité européenne 
Uma das características da Europa que Romain Gary vislumbra é a pluralidade de pátrias (ao invés de uma Europa supranacional), que confirma sua visão de busca da convivência com a alteridade. A escolha da França como sua pátria não foi aleatória, mas sim apoiada em uma forte influência da francofilia materna, confirmada por suas próprias impressões (ou talvez ficcionalizações da França). Apesar disso, o escritor insiste no plural como única possibilidade de construção da Europa:

O apego à pátria francesa (pátria que ainda por cima é a dos direitos do Homem) não é em nada incompatível com a consciência da unidade da cultura europeia. Ao contrário, no espírito de Gary, a coexistência de diferentes pátrias é um fator indispensável para a conservação do pluralismo cultural que faz a riqueza da Europa. Por outro lado, o objetivo último da Europa não poderia limitar-se à construção de uma potência econômica ou política, visto que na ótica garyana a Europa é principalmente uma potência espiritual. ${ }^{13}$ (LARAT, 1999, p. 141-142)

Enquanto potência espiritual, espera-se que a Europa pratique valores humanistas. Nos dois textos - Éducation européenne e As pipas -, Romain Gary aproveita o tema da guerra para sugerir um humanismo supra, que esteja acima de todas as características singularizantes, inclusive e sobretudo, a

qui ne serait pas le produit d'une réflexion académique, mais le résultat d'une expérience personnelle vécue et transcendée par l'écriture.".

${ }^{13}$ No original: "L'attachement à la patrie française (patrie qui plus est des droits de l'Homme) n'est nullement incompatible avec la conscience de l'unité de la culture européenne. Bien au contraire, dans l'esprit de Gary, la coexistence de différentes patries est un facteur indispensable pour le maintien du pluralisme culturel qui fait la richesse de l'Europe. Par ailleurs, le but ultime de l'Europe ne saurait se limiter à la construction d'une puissance économique ou politique, étant donné que dans l'optique garyenne, l'Europe est principalement une puissance spirituelle.". 
de nacionalidade. Assim, em Éducation européenne, à questão feita por Janek - "Por que os alemães fazem isso com a gente?" -Dobranski responde:

Por desespero. [...] Não são só os alemães. Isso está sempre rondando em qualquer lugar, desde sempre, em volta da humanidade. Assim que se aproxima demais, que penetra em você, o homem se faz alemão... mesmo que ele seja um patriota polonês. A questão é saber se o homem é alemão ou não... se acontece de ser somente às vezes. É isso que eu tento colocar em meu livro. ${ }^{14}$ (GARY, 1956, p. 76)

Nos dois textos, não há personagens alemães intrinsecamente maus que representariam o mal; em compensação, sempre há um personagem alemão que serve de contraponto à ideia de barbárie. Em Éducation européenne, Augustus Schröder, o fabricante de brinquedos que toca piano para Janek, se diz o último alemão. Em As pipas, Hans, o primo apaixonado por Lila e, consequentemente, rival de Ludo, dá falsas declarações para evitar a prisão do concorrente e ainda participa de um complô para matar Hitler. O general Von Tiele, na cozinha do restaurante Clos Joli, resume a ideia pluralista de Romain Gary: "Não é a mesma cultura, Marcellin. É por isso que precisamos um do outro..." (GARY, 1981, p. 169).

Em suas reflexões, Ludo se dá conta de que os alemães eram, de certa forma, um álibi bastante eficaz para esconder a maldade humana, que não leva em conta a nacionalidade:

Compreendia subitamente que as pessoas se serviam muito dos alemães, e mesmo dos nazistas, para se encobrirem. Uma ideia tinha vindo há muito tempo

\footnotetext{
${ }^{14}$ No original: "Par désespoir. [...] Il n'y a pas que les Allemands. Ça rôde partout, depuis toujours, autour de l'humanité... Dès que ça se rapproche trop, dès que ça pénètre en vous, l'homme se fait allemand... même s'il est un patriote polonais. La question est de savoir si l'homme est allemand ou non... s'il lui arrive seulement de l'être parfois. C'est ce que j'essaie de mettre dans mon livre.".
} 
alojar-se em meu espírito, da qual tive muita dificuldade para me livrar a seguir, e talvez nunca me tenha desembaraçado dela inteiramente. Os nazistas eram humanos. E o que havia de humano neles era a sua desumanidade. (GARY, 1981, p. 163-164)

Dessa forma, na contramão da opinião pública e da política francesa do pós-guerra, Romain Gary atribui um lugar importante para a Alemanha na Europa que vislumbrava:

Certo de que um dia a unificação alemã aconteceria e que a ruptura era apenas temporária, ele pensa que o objetivo da França não deveria ser de manter o esfacelamento da Alemanha, mas de assimilá-lo progressivamente: "dessa forma, o dia em que a Alemanha reencontrasse sua unidade, o retorno das províncias orientais constituiria para a União europeia um enriquecimento e não uma ameaça e um enfraquecimento." ${ }^{15}$ (LARAT, 1999, p. 83)

Em seu percurso humanista, o europeu Romain Gary sempre mantém a esperança no homem, um pouco como outro personagem, o bumanista Karl Loewy, fabricante de brinquedos, alemão e judeu, que acreditava no homem: "Platão, Montaigne, Erasmo, Descartes, Heine... Era preciso confiar nesses ilustres pioneiros; era preciso ter paciência, deixar ao humano o tempo de se manifestar, de se orientar na desordem e no mal-entendido, e de voltar ao comando"16 (GARY, 1962, p. 67). Se Romain Gary

\footnotetext{
${ }^{15}$ No original: "Certain que l'unité allemande se fera un jour et que la coupure n'est que provisoire, il pense que le but de la France ne devrait pas être de maintenir le morcellement de l'Allemagne mais de l'assimiler progressivement: 'de cette façon, le jour où l'Allemagne retrouvera son unité, le retour des provinces orientales constituerait pour l'Union européenne un enrichissement et non une menace et un ffaiblissement'.".

${ }^{16}$ No original: "Platon, Montaigne, Érasme, Descartes, Heine ... Il fallait faire confiance à ces illustres pionniers; il fallait patienter, laisser à l'humain le temps de se manifester, de s'orienter dans le désordre et le malentendu, et de reprendre le dessus.".
} 
não se esconde como esse personagem - que, para escapar ao antissemitismo de Hitler, se refugia em sua adega depois de ter levado para lá toda a sua biblioteca e ali permanece mesmo depois do fim da guerra -, ele também não participa diretamente de nenhum comitê ou fórum de estudos sobre a criação da União europeia. Aparentemente, prefere restringir sua ação ao campo da literatura. Seria legítimo dizer que sua recusa a toda e qualquer forma de heroicização o afastava do canteiro de construção da União europeia? Talvez ele acreditasse que não seria possível fazer do humanismo a referência de base dessa construção? De qualquer forma, ele seguiu o conselho que Ambroise Fleury dá a seu sobrinho:

É absolutamente evidente que um homem que devotou toda a sua vida às pipas possui em si uma semente de loucura. Só que há aqui uma questão de interpretação. Há os que chamam a isso "semente de loucura", outros falam também em "faísca sagrada". Às vezes, é difícil distinguir uma da outra. Mas se você realmente amar alguém ou alguma coisa, dê-lhe tudo o que tem e mesmo tudo o que é, e não se preocupe com o resto... (GARY, 1981, p. 6)

Os personagens de Romain Gary apresentam as ideias humanistas do escritor que se engajou pelo viés da escrita. Esses personagens, Ambroise Fleury, Ludo, Dobranski, Janek, aos quais se juntam Tulipe, Morel, Johnny Coeur e tantos outros, se empenham em mostrar o desperdício de forças e de talento dos homens que não reconhecem a humanidade enquanto um valor intrínseco e essencial ao homem.

Paul Audi, filósofo e amigo de Romain Gary, destaca um aspecto importante do percurso do escritor que o aproxima bastante desses personagens: 
[...] um homem que tinha dentro de si a capacidade insigne de se colocar no lugar de todo mundo, de estar na pele de cada um, um tal poder de empatia o tendo conduzido não apenas a se tornar o escritor que conhecemos, mas, quando se tratava, para ele, de se expressar sobre questões fundamentais relativas à humanidade do homem, a se colocar então na situação de qualquer um, única maneira para ele de cumprir o que acreditava ser sua tarefa espiritual: usar todas as suas forças para defender a fragilidade humana. ${ }^{17}$ (AUDI, 2007, p. 106-107)

Nesse movimento de se ver e se colocar no lugar do outro, a recusa ao esquecimento - que por vezes se apresenta como omissão - desempenha papel importante: a lembrança se transforma em solidarização com o drama individual e do grupo, favorecendo a construção da fraternidade sonhada por Romain Gary.

O tema da guerra atravessa a obra de Romain Gary em vários momentos, mas o primeiro e o último livros lhe são inteiramente dedicados. Nesses dois textos, o discurso tramado com os fios da memória e da ficção ganha ares de um singular memorial onde as lembranças individualizadas do horror ilustram atitudes devidas a uma humanidade (no sentido de caráter intrínseco do ser humano) que é necessário reestruturar.

De certa maneira, As pipas concluem o cumprimento da promessa feita por Janek a Dobranski agonizante, em Éducation européenne:

${ }^{17}$ No original: "un homme qui avait en lui la capacité insigne de se mettre à la place de tout le monde, de se glisser dans la peau de tout un chacun, une telle puissance d'empathie l'ayant conduit non seulement à devenir le romancier que l'on sait, mais, quand il s'est agi pour lui de s'exprimer sur des questions fondamentales touchant à l'humanité de l'homme, à se placer alors dans la situation de n'importe qui, seule façon pour lui d'accomplir ce qu'il estimait être sa tâche spirituelle: mettre toutes ses forces dans la défense de la fragilité humaine.". 
- Não tive tempo de terminar meu livro.

- Você vai terminá-lo.

- Não, te peço para terminá-lo para mim [...].

- Prometo.

- Fale com eles da fome e do grande frio, da esperança e do amor.

- Vou falar.

- Gostaria que eles tivessem orgulho de nós e vergonha...

- Eles terão orgulho deles e vergonha de nós.

- Tente... É preciso que saibam... É preciso que não esqueçam... Diga-lhes...

- Eu direi tudo. ${ }^{18}$ (GARY, 1956, p. 281)

Na pena de Romain Gary, dizer tudo significa confrontar o homem com os problemas que ele cria para viver com o outro. Nesse sentido, as classificações simplistas - tais como a identificação do alemão com o mal -, ainda que fundamentadas, às vezes, em exemplos abundantes, são, na verdade, armadilhas contra o próprio homem. A desumanização desse outro sendo impossível, é preciso vê-lo como um duplo do mesmo.

No projeto humanista de Romain Gary, somente a percepção dessa dificuldade poderia contribuir para a criação de um novo conceito de humanidade no qual o mesmo e o outro poderiam perceber também suas semelhanças e se reconhecerem, ambos, como seres humanos.

${ }^{18}$ No original: “- Je n'ai pas eu le temps de finir mon livre./ - Tu le finiras. / Non. Je te demande de le finir pour moi. [...]. / - Je te promets. / - Parle-leur de la faim et du grand froid, de l'espoir et de l'amour. / - Je leur en parlerai. / - Je voudrais qu'ils soient fiers de nous et qu'ils aient honte .... / - Ils seront fiers d'eux et auront honte de nous. / - Essaie... Il faut qu'ils sachent... Il ne faut pas qu'ils oublient... Dis-leur... / - Je leur dirai tout.”. 


\section{Referências}

AUDI, P. Je me suis toujours été un autre: le paradis de Romain Gary. Paris: Christian Bougois, 2007.

GARY, R. Éducation européenne. Paris: Gallimard, 1956 [édition définitive]. (Coll. Folio $\mathrm{n}^{\circ}$ 203).

GARY, R O rouxinol sempre retorna. Trad. de Aydano Arruda. São Paulo: Ibrasa, 1961.

GARY, R. Les Oiseaux vont mourir au Pérou. Paris: Gallimard, 1962. (Coll. Folio $\mathrm{n}^{\circ}$ 668).

GARY, R. La vie devant soi. Paris: Mercure de France, 1975. (Coll. Folio $\mathrm{n}^{\mathrm{o}}$ 1362).

GARY, R. Les cerfs-volants. Paris: Gallimard, 1980. (Coll. Folio n $\left.{ }^{\circ} 1467\right)$.

GARY, R. As pipas. Trad. de Celina Portocarrero. Rio de Janeiro: Francisco Alves, 1981.

GARY, R. Toda a vida pela frente. Trad. de Herbert Maciel e Cláudio Mesquita. Rio de Janeiro: Rocco, 1986.

LARAT, F. Romain Gary: un itinéraire européen. Chêne-Bour: Georg, 1999.

ORDRE de la Libération. Site oficial: http://www.ordredelaliberation.fr/ fr_doc/1_1_2_creation.html Acesso em 8 de outubro de 2009.

RICOEUR, P. La mémoire, l'bistoire, l'oubli. Paris: Seuil, 2000. (Coll. Points Série Essais n ${ }^{\circ}$ 494).

SCHOOLCRAFT, R. Dialogue de la mémoire et de l'histoire chez Romain Gary. In: ROUMETTE, J. (Dir.) Littératures: Romain Gary: l'ombre de l'histoire. Toulouse: Presses Universitaires du Mirail, 2007. № 56.

TODOROV, T. Mémoire du mal tentation du bien: enquête sur le siècle. Paris: Robert Laffont, 2000.

TODOROV, T. Romain Gary : la géographie de la mémoire. In: SACOTTE, M. (Dir.) Romain Gary et la pluralité des mondes. Paris: PUF, 2002.

YAD VASHEM. Site oficial: http://www.yadvashem.org/ Acesso em 15 de dezembro de 2013. 
